Research Article

\title{
Determination of Tobramycin in M9 Medium by LC-MS/MS: Signal Enhancement by Trichloroacetic Acid
}

\author{
Liusheng Huang $\mathbb{D}^{1},{ }^{1}$ Janus Anders Juul Haagensen, ${ }^{2}$ Davide Verotta ${ }^{(D)},{ }^{1}$ Vincent Cheah, ${ }^{1}$ \\ Alfred M. Spormann, ${ }^{3}$ Francesca Aweeka, ${ }^{1}$ and Katherine Yang $\mathbb{D D}^{1}$ \\ ${ }^{1}$ Department of Clinical Pharmacy, School of Pharmacy, University of California San Francisco, San Francisco, CA, USA \\ ${ }^{2}$ Novo Nordisk Foundation Center for Biosustainability, Technical University of Denmark, 2800 Kongens Lyngby, Denmark \\ ${ }^{3}$ Department of Civil and Environmental Engineering, Stanford University, Palo Alto, CA, USA
}

Correspondence should be addressed to Liusheng Huang; liusheng.huang@ucsf.edu and Katherine Yang; Katherine.Yang2@ucsf.edu

Received 8 December 2017; Accepted 6 February 2018; Published 26 April 2018

Academic Editor: Lucia Mendez

Copyright (c) 2018 Liusheng Huang et al. This is an open access article distributed under the Creative Commons Attribution License, which permits unrestricted use, distribution, and reproduction in any medium, provided the original work is properly cited.

\begin{abstract}
It is well known that ion-pairing reagents cause ion suppression in LC-MS/MS methods. Here, we report that trichloroacetic acid increases the MS signal of tobramycin. To support studies of an in vitro pharmacokinetic/pharmacodynamic simulator for bacterial biofilms, an LC-MS/MS method for determination of tobramycin in $\mathrm{M}_{9}$ media was developed. Aliquots of $25 \mu \mathrm{L} \mathrm{M}_{9}$ media samples were mixed with the internal standard (IS) tobramycin- $\mathrm{d}_{5}(5 \mu \mathrm{g} / \mathrm{mL}, 25 \mu \mathrm{L})$ and $200 \mu \mathrm{L} 2.5 \%$ trichloroacetic acid. The mixture $(5 \mu \mathrm{L})$ was directly injected onto a PFP column $(2.0 \times 50 \mathrm{~mm}, 3 \mu \mathrm{m})$ eluted with water containing $20 \mathrm{mM}$ ammonium formate and $0.14 \%$ trifluoroacetic acid and acetonitrile containing $0.1 \%$ trifluoroacetic acid in a gradient mode. ESI ${ }^{+}$and MRM with ion $\mathrm{m} / z \quad 468 \rightarrow 324$ for tobramycin and $\mathrm{m} / z 473 \rightarrow 327$ for the IS were used for quantification. The calibration curve concentration range was $50-25000 \mathrm{ng} / \mathrm{mL}$. Matrix effect from $\mathrm{M}_{9}$ media was not significant when compared with injection solvents, but signal enhancement by trichloroacetic acid was significant ( $\sim 3$ fold). The method is simple, fast, and reliable. Using the method, the in vitro PK/PD model was tested with one bolus dose of tobramycin.
\end{abstract}

\section{Introduction}

Tobramycin (TBM) is an aminoglycoside antibiotic widely used for the treatment of multidrug-resistant Gram-negative bacterial infections by inhibiting protein synthesis and altering integrity of the bacterial cell membrane [1]. It is also named 3 -deoxykanamycin B, nebramycin 6 , and chemically O-3-amino-3-deoxy- $\alpha$-D-glucopyranosyl-(1-6)-O-[2,6-diamino-2,3,6-trideoxy- $\alpha$-D-ribo-hexopyranisyl-(1-4)]-2-deoxyD-streptamine (Figure 1). It is water soluble and stable at ambient temperature at a wide range of $\mathrm{pH}$ 1-11 [2].

To support pharmacokinetic (PK) and pharmacodynamic (PD) studies of TBM for biofilm-mediated infections using an in vitro model, an analytical method to quantitate TBM in $\mathrm{M}_{9}$ medium is needed. Two considerable challenges in determination of TBM in biological matrices are (1) poor retention on commonly used reverse-phase HPLC columns due to its higher hydrophilicity and (2) lack of chromophores for detection. Numerous assays have been reported including HPLC coupled with UV [3], electrochemical [4, 5], or fluorescence detectors [6], and these assays lack sensitivity and usually require derivatization. LC-MS/MS assays have also been reported, but the sensitivity of these assays requires concentrations $\geq 100 \mathrm{ng} / \mathrm{mL}$ [7-9]. Trichloroacetic acid (TCA) has been used in sample preparation to remove proteins, especially for hydrophilic analytes, with the advantage of direct injection of resulting sample solution [10]. We found that TCA not only increased the retention time but also the MS signal of TBM. Built on this observation, we report a simple LC-MS/MS method to determine TBM in $\mathrm{M}_{9}$ medium using TCA as the ion pair reagent in the injection sample instead of the mobile phase. In addition, this assay utilized a PFP column, which yielded a better retention factor for TBM $(k=1.8)$. The calibration range was $50-25000 \mathrm{ng} / \mathrm{mL}$. 


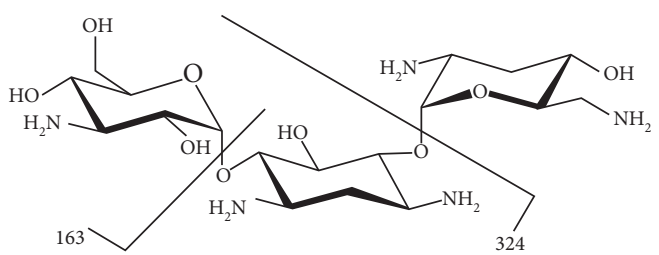

(a)
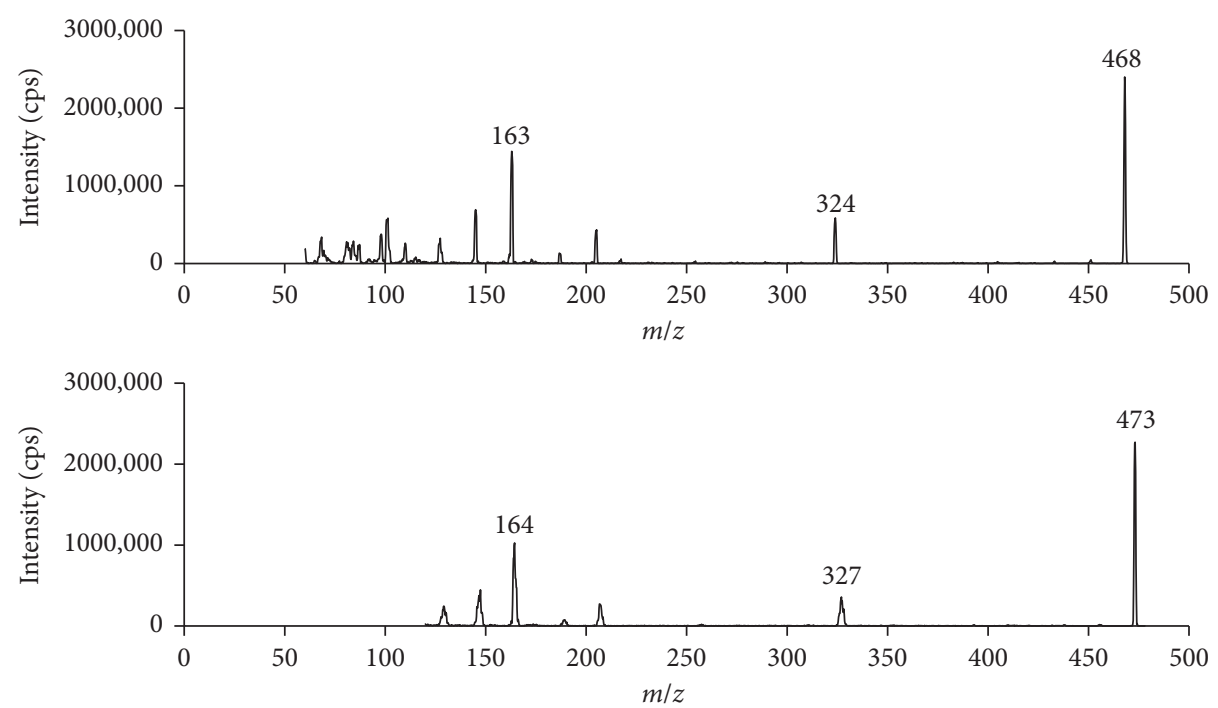

(b)

Figure 1: Product ion spectra of tobramycin (a) and deuterated tobramycin (b).

\section{Experimental}

2.1. Chemicals and Reagents. Tobramycin was purchased from Sigma-Aldrich (St. Louis, MO, USA). Deuterated tobramycin $\left(\mathrm{TBM}^{-\mathrm{d}_{5}}\right.$ ) was purchased from Toronto Research Chemicals (North York, Ontario, Canada). Formulated tobramycin $(20 \mathrm{mg} / 2 \mathrm{~mL}$, for IM or IV use) was obtained from APP Pharmaceuticals, LLC (Schaumburg, IL, USA). Common solvents (HPLC grade) and reagents (Certified ACS) were obtained from Thermo-Fisher Sci. (Fair Lawn, NJ, USA). $\mathrm{M}_{9}$ minimal salts $\times 5$ solution was prepared by dissolving $2.82 \mathrm{~g} \mathrm{Difco}^{\mathrm{TM}} \mathrm{M}_{9}$ minimal salts (BD, Sparks, MD, USA) in $50 \mathrm{~mL}$ water. $\mathrm{M}_{9}$ medium was prepared by adding $10 \mathrm{~mL} \mathrm{M}_{9}$ minimal salts $\times 5$ solution, $5 \mu \mathrm{L} 1 \mathrm{M} \mathrm{CaCl}_{2}, 50 \mu \mathrm{L}$ $1 \mathrm{M} \mathrm{MgSO}_{4}$, and $13.5 \mu \mathrm{L} 20 \%$ glucose to $40 \mathrm{~mL}$ water.

2.2. Instrumental. The LC-MS/MS system consists of an AB Sciex API5000 Tandem Mass Spectrometer, two Shimadzu Prominence $20 \mathrm{AD}^{\mathrm{XR}}$ UFLC pumps, and an SIL-20AC ${ }^{\mathrm{XR}}$ autosampler managed with Analyst ${ }^{\circledR}$ 1.6.2 (AB Sciex, Redwood City, CA, USA). The gases for the MS system were supplied by an LC-MS gas generator (Source 5000 ${ }^{\mathrm{TM}}$, Parker Balston Inc., Haverhill, MA, USA). LC conditions were as follows: separation was achieved on a Pursuit PFP column $(2.1 \times 50 \mathrm{~mm}, 3 \mu \mathrm{m})$ (Agilent Tech. Inc., Santa Clara, CA, USA). Mobile phase A was $20 \mathrm{mM} \mathrm{NH}_{4} \mathrm{FA} 0.14 \%$ trifluoroacetic acid (TFA) and B was $0.1 \%$ TFA in acetonitrile (MeCN). Five-microliter sample was injected onto the column eluted at a flow rate of $0.4 \mathrm{~mL} / \mathrm{min}$ in a gradient program consisting of $5 \%$ solvent $\mathrm{B}(0-0.10 \mathrm{~min})$, from 5 to $20 \% \mathrm{~B}(0.10-1.50 \mathrm{~min})$, from 20 to $80 \% \mathrm{~B}(1.50-$ $1.51 \mathrm{~min}), 80 \% \mathrm{~B}(1.51-2.00 \mathrm{~min}), 80 \%-5 \% \mathrm{~B}$ (2.00-2.01 min), and $5 \% \mathrm{~B}$ (2.01-3.00 min). Retention times for TBM and the internal standard (IS) were both $0.84 \mathrm{~min}$. The divert valve was set to direct the LC eluent to the mass spectrometer (MS) source at $0.6 \mathrm{~min}$ and to the waste line at $2.9 \mathrm{~min}$. The MS conditions for TBM and the IS were optimized by separate infusion of $200 \mathrm{ng} / \mathrm{mL}$ TBM and $400 \mathrm{ng} / \mathrm{mL}$ deuterated TBM in $0.1 \%$ formic acid into the MS at a flow rate of 15 and $25 \mu \mathrm{L} / \mathrm{min}$ constantly while adjusting MS parameters with autotune followed by manual adjustment to achieve the maximal signal. The ions $m / z 468 \rightarrow 324$ for TBM and $m / z$ $473 \rightarrow 327$ for the IS were used for quantification in the multiple reaction monitoring (MRM) mode. The optimized compound-dependent MS parameters were $121 \mathrm{~V}$ (DP), $21 \mathrm{~V}$ (CE), and $26 \mathrm{~V}$ (CXP) for both TBM and the IS. DP was declustering potential, CE was collision energy, and CXP was collision cell exit potential. The instrument-dependent parameters were optimized by flow injection analysis (FIA): an aliquot of $5 \mu \mathrm{L} 200 \mathrm{ng} / \mathrm{mL}$ TBM was repeatedly injected into the LC-MS/MS system while LC flow was maintained at $0.4 \mathrm{~mL} / \mathrm{min} 50 \% \mathrm{~B}$ isocratically without column in the line. The optimized MS parameters were as follows: MS source was the Turbolon Spray ionization in positive mode $\left(\mathrm{ESI}^{+}\right)$with turbo heater set at $500^{\circ} \mathrm{C}$, curtain gas was nitrogen at $40 \mathrm{psi}$, nebulizer gas (gas 1) and auxiliary (Turbo) gas (gas 2) were zero air set at 50 psi and 60 psi, respectively, collision-deactivated 
association gas was nitrogen at $12 \mathrm{psi}$, and ionspray voltage was 5500 V. Data were processed with Analyst 1.6.2. (AB Sciex, Redwood City, CA, USA).

\subsection{Preparation of Calibrators, Quality Controls, and Internal} Standard. As TBM used in the in vitro biofilm PK/PD model contains formulation ingredients, calibrators and quality controls (QCs) were prepared from formulated TBM $(20 \mathrm{mg} / 2 \mathrm{~mL})$ with serial dilution in $\mathrm{M}_{9}$ medium to match the matrix in unknown samples. Calibrators consists of 50, 100, 250, $500,1000,2500,5000,10000$, and $25000 \mathrm{ng} / \mathrm{mL}$. QCs consist of $150,1500,20000$, and $40000 \mathrm{ng} / \mathrm{mL}$, designated as low-, medium-, high-, and extrahigh QC. The internal standard TBM- $\mathrm{d}_{5}$ solution was prepared in water by serial dilution at a final concentration of $5000 \mathrm{ng} / \mathrm{mL}$. The IS solution needs to stand on bench overnight before use.

2.4. Sample Preparation. $\mathrm{M}_{9}$ samples $(25 \mu \mathrm{L})$ were pipetted into $1 \mathrm{~mL}$ glass autosampler vials, to which were added $25 \mu \mathrm{L}$ IS $\left(5 \mu \mathrm{g} / \mathrm{mL} \mathrm{TBM}^{\left.-\mathrm{d}_{5}\right)}\right.$ and $200 \mu \mathrm{L} 2.5 \%$ TCA. After vortex mixed, the samples were placed in the autosampler tray. If the samples were collected from $\mathrm{M}_{9}$ medium flowing through bacterial biofilm, the samples were centrifuged at $20000 \mathrm{~g}$ for $3 \mathrm{~min}$ before adding to the sample vial. Injection volume was $5 \mu \mathrm{L}$.

2.5. Validation. The method was validated in terms of precision, accuracy, matrix effect, and stability, following the procedures as described previously [10]. One set of calibrators was processed for each run and injected in the beginning of the batch run. Calibration curves were constructed by linear regression of the peak area ratio of the analyte to the IS ( $y$-axis) versus the nominal analyte concentrations ( $x$-axis) with a weighting factor of $1 / x$. The lower limit of quantification (LLOQ) was established with precision and accuracy $<20 \%$. Intraday precision and accuracy were determined by analysis of at least five replicates of each QC sample at low (150 ng/mL), medium (1500 ng/mL), and high $(20000 \mathrm{ng} / \mathrm{mL})$ concentration levels extracted with a set of calibrators in one batch. The same procedure was repeated on at least 2 different days with new samples to determine interday precision and accuracy (total: $n \geq 15$ per concentration level). Precision was reported as relative standard deviation (RSD) and accuracy as percent deviation from the nominal concentration ( $\%$ dev.). Matrix effect was evaluated as follows: TBM was spiked at the concentrations of 300 , 1500 , and $20000 \mathrm{ng} / \mathrm{mL}$ in water and $\mathrm{M}_{9}$ medium, respectively. Three aliquots of each sample were processed as described above (Section 2.4). The peak areas and peak area ratios of TBM in $\mathrm{M}_{9}$ medium were compared to those in water. Values within $100 \pm 15 \%$ were considered as no significant matrix effect from $\mathrm{M}_{9}$ medium. To evaluate partial volume accuracy, $12.5 \mu \mathrm{L}$ extrahigh QC at $40000 \mathrm{ng} / \mathrm{mL}$ was mixed with $12.5 \mu \mathrm{L} \mathrm{M}$ medium and processed as described in Section 2.4. Stability was evaluated in the following conditions: room temperature $\left(21-25^{\circ} \mathrm{C}\right)$ for 5 days, 3 days on the autosampler rack, 3 freeze-thaw cycles, and 6 days at $-70^{\circ} \mathrm{C}$. Stability of freshly prepared IS working solution was evaluated at room temperature for $24 \mathrm{hr}$ and 5 days. Effects of concomitant drugs (e.g., meropenem and colistin) on quantification were evaluated by spiking them in the QC samples at a final concentration of $110 \mu \mathrm{g} / \mathrm{mL}$ meropenem (MP) and $20 \mu \mathrm{g} / \mathrm{mL}$ colistin. The measured concentrations of TBM were compared to the QC samples without these concomitant drugs.

2.6. Application. This method was used to validate a novel dynamic PK/PD model designed to study the effects of humansimulated antibiotic concentrations on Pseudomonas aeruginosa biofilms grown in vitro [11]. TBM, in conjunction with a $\beta$-lactam antibiotic such as MP, is recommended for the treatment of multidrug-resistant Pseudomonas aeruginosa lung infection in patients with cystic fibrosis [12]. While the formation of bacterial biofilms in the lung is a characteristic of chronic lung infection in patients with cystic fibrosis, the PD of antibiotics on biofilms is largely unknown. The concentrationtime curves of single and multiple intravenous bolus doses of TBM were simulated based on human population PK parameters [13]. The target TBM peak concentration, based on a dose of $10 \mathrm{mg} / \mathrm{kg}$ in a $70 \mathrm{~kg}$ adult, was $32.79 \mathrm{mg} / \mathrm{L}$ with an associated $t_{1 / 2}=2.75 \mathrm{~h}$. Samples were taken at $t=0,1,2,4,6,8$, 16 , and $24 \mathrm{hr}$ from the main feeding bottle and the tubing outlets from three flow cells with bacterial biofilm. All samples were shipped to our analytical lab on the same day with dry ice overnight delivery and stored at $-70^{\circ} \mathrm{C}$ freezer until analysis. Samples were typically analyzed within a week.

\section{Results and Discussion}

3.1. LC-MS/MS Optimization. TBM contains five amine groups (Figure 1), making electrospray ionization in positive mode $\left(\mathrm{ESI}^{+}\right)$the choice of the ion source. The ion $\mathrm{m} / \mathrm{z}$ $468 \rightarrow 324$ was chosen for quantification for its signal abundancy and selectivity. Compared to product ion $m / z 163$, $m / z 324$ has less background signal. The deuterated TBM was used as the IS. However, the deuteration positions were not identified. MS scan showed that multiple forms of deuterated TBM exist, with the most abundant protonated molecule at $m / z$ 473. Therefore, ion $m / z 473 \rightarrow 327$ was chosen for the IS. The signal of the ion $m / z 473 \rightarrow 327$ decreased gradually in the first few hours but remained stable after the IS solution stood on bench overnight. These observations suggested that deuteration most likely occurred on amine groups, and the stable form of IS contains a deuterium atom on each amine group (Figure 1).

Having 5 amine groups and 5 hydroxyl groups also makes TBM hardly retain on reverse-phase LC columns. Ion pair reagent TFA and TCA in the mobile phase could help to retain polar amino molecules on the reverse-phase columns; however, sensitivity may be compromised due to ion suppression. Previously, we found that TFA could change retention time of isoniazid when added into sample before injection (Supplementary Material Figure S1). However, TFA did not improve the TBM peak. Cheng et al. used TCA to modify retention time of aminoglycoside compounds [14]. 


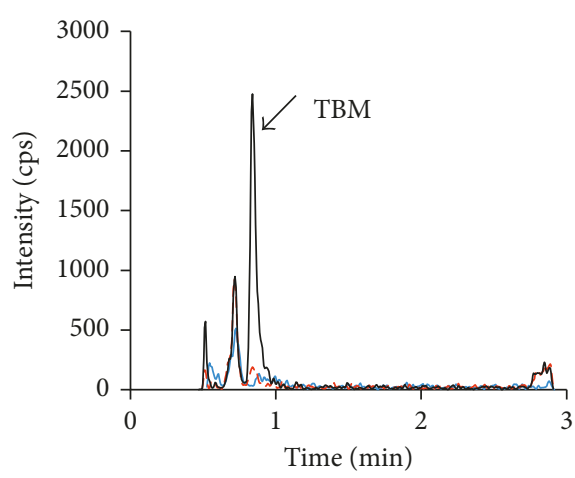

(a)

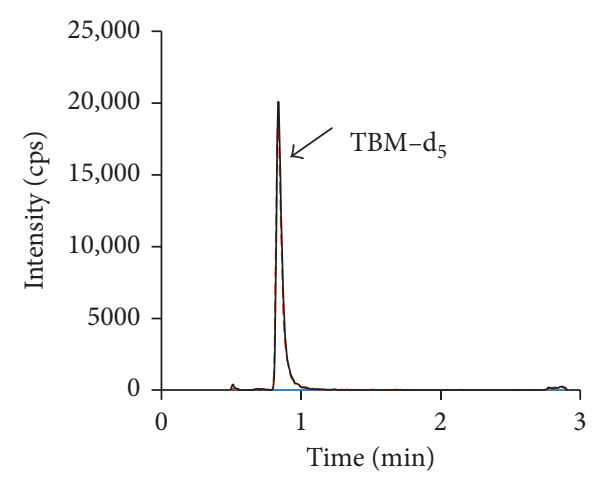

(b)

FIgURE 2: Chromatograms of blank $\mathrm{M}_{9}$ medium (blue solid line), blank $\mathrm{M}_{9}$ medium spiked with IS (red dash line), and TBM at LLOQ level (black solid line). (a) TBM channel; (b) the IS channel.

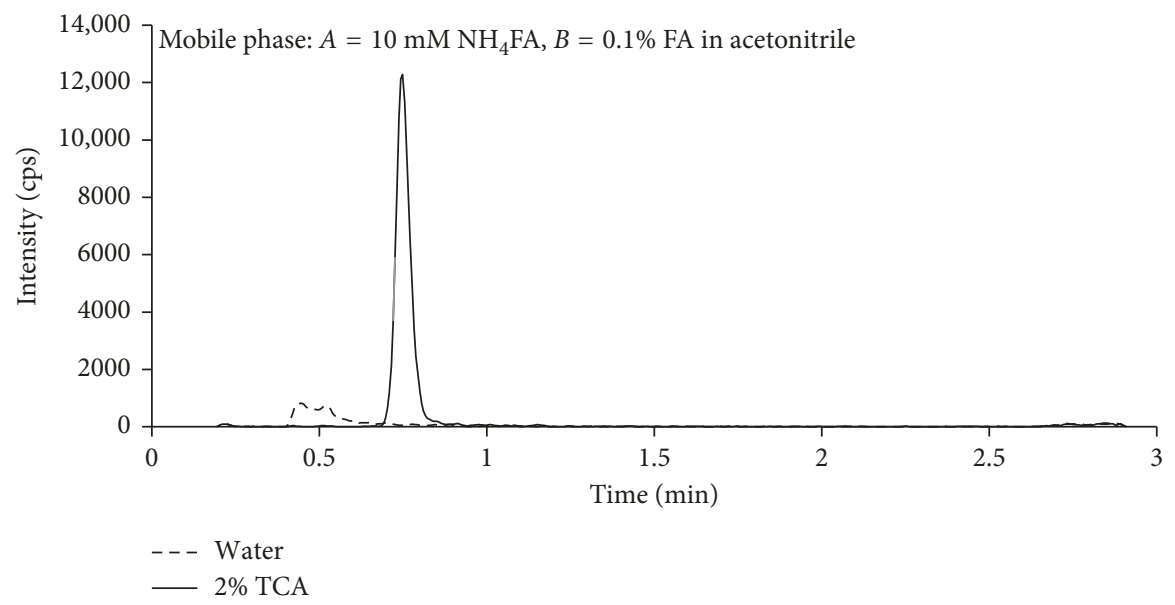

(a)

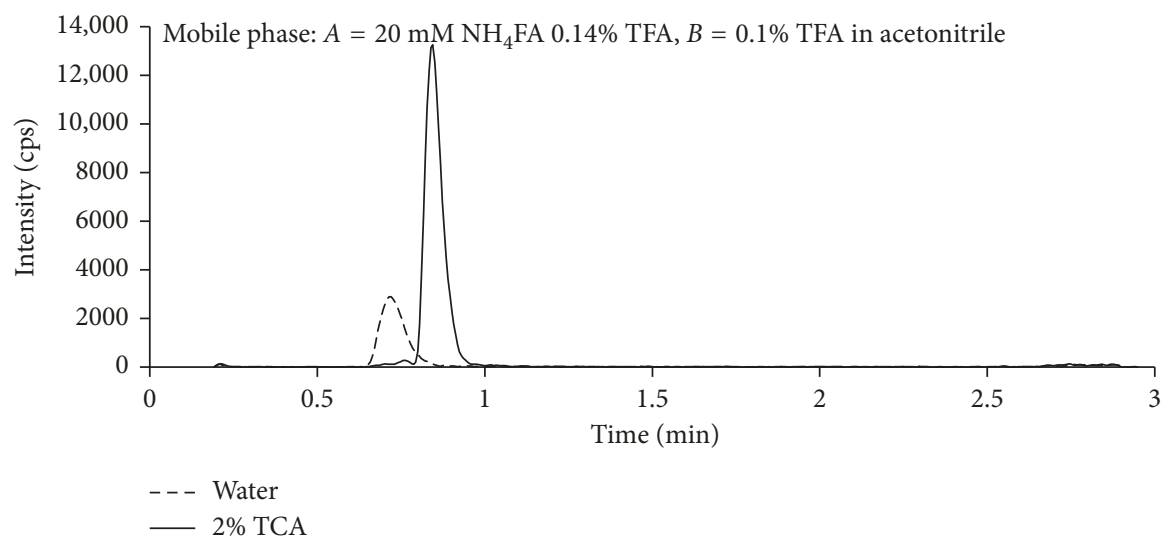

(b)

FIGURE 3: Impact of mobile phase solvents and sample solvents on peak shape, retention time, and signal intensity of TBM. Sample solvents: water (dash line) and 2\% TCA (solid line). Mobile phase solvents: $10 \mathrm{mM} \mathrm{NH}_{4} \mathrm{FA}(\mathrm{pH} 4.0)-0.1 \% \mathrm{FA}$ in MeCN (a) and $20 \mathrm{mM} \mathrm{NH}_{4} \mathrm{FA} 0.14 \%$ TFA- $0.1 \%$ TFA in MeCN (b).

We found that when the sample contained 2\% TCA with a $5 \mu \mathrm{L}$ injection volume, longer retention time of TBM was observed (Supplementary Material Figure S2). Under the final LC condition, the TBM peak was sufficiently separated from the matrix-generated peaks (Figure 2). The retention time $t_{\mathrm{R}}=0.839 \mathrm{~min}$, the estimated dead volume is $0.68 \pi r^{2} L=0.118 \mathrm{~mL}$, and retention factor $k=1.84$.

Unexpectedly, TCA also enhanced MS response of TBM. Two different sample solvents (water and 2\% TCA) and two sets of mobile phase solvents were tested: (1) $A=10 \mathrm{mM}$ 
TABLE 1: Interday average backcalculated standard concentrations $(n=3)$.

\begin{tabular}{lcccccccccc}
\hline Nominal concentration $(\mathrm{ng} / \mathrm{mL})$ & 50 & 100 & 250 & 500 & 1000 & 2500 & 5000 & 10000 & 25000 & $R$ \\
Mean (ng/mL) & 50.1 & 91.6 & 236 & 521 & 1043 & 2663 & 4973 & 9977 & 24800 & 0.9992 \\
Precision (RSD, \%) & 3.82 & 6.11 & 3.31 & 2.98 & 3.37 & 2.50 & 8.06 & 3.72 & 2.91 & 0.0379 \\
Accuracy (\% dev.) & 0.13 & -8.37 & -5.60 & 4.13 & 4.33 & 6.53 & -0.53 & -0.23 & -0.80 & 3 \\
$n$ & 3 & 3 & 3 & 3 & 3 & 3 & 3 & 3 & 3 \\
\hline
\end{tabular}

TABLE 2: Intra- and interday precision and accuracy.

\begin{tabular}{|c|c|c|c|c|c|c|c|c|}
\hline \multirow[b]{2}{*}{ Nominal (ng/mL) } & \multicolumn{4}{|c|}{ Intraday } & \multicolumn{4}{|c|}{ Interday } \\
\hline & 50.0 & 150 & 1500 & 20000 & 50.0 & 150 & 1500 & 20000 \\
\hline Mean (ng/mL) & 43.0 to 50.9 & 150 to 159 & 1533 to 1653 & 20450 to 20650 & 46.8 & 153 & 1591 & 20572 \\
\hline Precision (RSD) (\%) & 3.0 to 16.9 & 4.4 to 6.7 & 2.1 to 3.5 & 2.5 to 3.4 & 8.43 & 3.33 & 3.78 & 0.52 \\
\hline Accuracy (dev.) (\%) & -14.0 to 1.7 & 0 to 5.9 & 2.2 to 10.2 & 2.3 to 3.3 & -6.44 & 1.96 & 6.04 & 2.86 \\
\hline$n$ & 6 & 6 & 6 & 6 & 3 & 3 & 3 & 3 \\
\hline
\end{tabular}

TABLE 3: Matrix effect.

\begin{tabular}{|c|c|c|c|c|c|c|c|c|c|}
\hline \multirow{2}{*}{ Concentration $(\mathrm{ng} / \mathrm{ml})$} & \multicolumn{2}{|c|}{ TBM peak area $\left(\times 10^{4}\right)$} & \multicolumn{2}{|c|}{ IS peak area $\left(\times 10^{4}\right)$} & \multicolumn{2}{|c|}{ Ratio } & \multicolumn{3}{|c|}{ Matrix effect } \\
\hline & Water & $\mathrm{M}_{9}$ & Water & $\mathrm{M}_{9}$ & Water & $\mathrm{M}_{9}$ & TBM & IS & Ratio \\
\hline Low (120) & $3.60 \pm 0.12$ & $3.83 \pm 0.13$ & $8.26 \pm 0.49$ & $8.72 \pm 0.53$ & 0.436 & 0.439 & 106 & 106 & 101 \\
\hline Medium (1500) & $18.1 \pm 1.0$ & $20.0 \pm 1.4$ & $8.80 \pm 0.77$ & $9.30 \pm 0.91$ & 2.06 & 2.15 & 110 & 106 & 104 \\
\hline High (17000) & $378 \pm 5$ & $413 \pm 18$ & $13.7 \pm 0.5$ & $14.7 \pm 0.7$ & 27.6 & 28.1 & 109 & 107 & 102 \\
\hline
\end{tabular}

Data represent the mean peak area $( \pm \mathrm{SD})$ from triplicate analysis.

$\mathrm{NH}_{4} \mathrm{FA}$ at $\mathrm{pH} 4.0 ; B=0.1 \% \mathrm{FA}$ in $\mathrm{MeCN}$ and (2) $A=20 \mathrm{mM}$ $\mathrm{NH}_{4} \mathrm{FA} 1.4 \%$ TFA; $B=0.1 \%$ TFA in MeCN, using the same gradient elution method. With the commonly used mobile phase solvents (set 1), the peak shape for TBM was poor if injection solvent is water, while $2 \%$ TCA in the sample improved peak shape, signal intensity, and retention time significantly (Figure 3(a)); with mobile phase solvent set 2, the signal intensity and retention time of TBM improved further (Figure 3(b)). This improvement is critical as the interference peak from $\mathrm{M}_{9}$ medium was then separated from the TBM peak (Figure 2). The exact mechanism of signal enhancement by TCA is unknown. Cheng et al. thought that reduced matrix effect with longer retention time contributed to the signal enhancement [14], but we observed signal enhancement in neat solution (Figure 3 ). The possible reason could be that TCA limited multiple charges of TBM and thus increased monocharged molecular ion $\left([\mathrm{M}+\mathrm{H}]^{+}\right)$. In addition, we observed that MS response of the IS $\left(\mathrm{TBM}^{\left.-\mathrm{d}_{5}\right)}\right.$ was also increased with the increase of TBM concentration, suggesting ion enhancement of coeluting compounds. This should not affect quantification as IS was added to all samples, and the TBM signal increased accordingly. This was confirmed with the excellent linearity of calibration curve.

3.2. Validation. Based on our initial simulation, the TBM trough concentration is expected to be $>250 \mathrm{ng} / \mathrm{mL}$. Therefore, the LLOQ in this assay was initially set at $250 \mathrm{ng} / \mathrm{mL}$, the upper limit of quantification was set at $25000 \mathrm{ng} / \mathrm{mL}$, and validation was performed with low (300 $\mathrm{ng} / \mathrm{mL})$, medium $(1500 \mathrm{ng} / \mathrm{mL})$, and high (20000 ng/mL) QCs. After tested the in vitro biofilm model, we found that the trough TBM concentration fell below $250 \mathrm{ng} / \mathrm{mL}$, and thus, we lowered the LLOQ to $50 \mathrm{ng} / \mathrm{mL}$ and the low QC level to $150 \mathrm{ng} / \mathrm{mL}$ accordingly. Validation of intraday/interday precision and accuracy and interference of concomitant drugs were repeated with the new low QC concentration.

3.2.1. Calibration Range. At the LLOQ concentration (50 ng/mL), the signal intensity was $2100-2400 \mathrm{cps}$ (peak area, 6600-7900) and signal-to-noise ratio $S / N=30-48$ (Figure 2). This LLOQ is lower than others reported in literature. A recent study reported an LLOQ at $100 \mathrm{ng} / \mathrm{mL}$. The detector was the same as ours, but heptafluorobutyric acid was used as ion pair reagent in the mobile phase and sample reconstitution [9]. The calibration curve was constructed with least square linear regression weighted by $1 / x$. The interday backcalculated concentrations of calibrators over 3 days are listed in Table 1 . The precision is within $10 \%$ and accuracy (percent deviation from the nominal value) is within $\pm 10 \%$, too. Representative MRM ion chromatograms of TBM from $\mathrm{M}_{9}$ medium (double blank), $\mathrm{M}_{9}$ medium spiked with IS (blank), and LLOQ samples are shown in Figure 2.

3.2.2. Precision and Accuracy. The intraday precision $(n=6)$ was within $7 \%$ at low, medium, and high concentrations. The interday precision, calculated with the individual mean concentration from 3 days, was within $5 \%$ at the three concentration levels. The intra- and interday accuracy was all within $15 \%$. At the LLOQ levels, the precision and accuracy met the criteria of $<20 \%$ (Table 2 ).

3.2.3. Matrix Effect. The matrix effect of $\mathrm{M}_{9}$ medium on both TBM and IS signals is within $100 \pm 15 \%$ (Table 3), suggesting that the matrix effect of $\mathrm{M}_{9}$ medium was not significant. The matrix effect on the peak area ratio was 
TABLE 4: Stability of TBM.

\begin{tabular}{|c|c|c|c|}
\hline Conditions & $\%$ remained & RSD (\%) & $n$ \\
\hline \multicolumn{4}{|l|}{ In autosampler vial, $21-25^{\circ} \mathrm{C}, 3$ days } \\
\hline $300 \mathrm{ng} / \mathrm{mL}$ & 107 & 3.5 & 3 \\
\hline $20000 \mathrm{ng} / \mathrm{mL}$ & 105 & 2.4 & 3 \\
\hline \multicolumn{4}{|l|}{ In $\mathrm{M}_{9}, 21-25^{\circ} \mathrm{C}, 5$ days } \\
\hline $300 \mathrm{ng} / \mathrm{mL}$ & 104 & 8.1 & 3 \\
\hline $20000 \mathrm{ng} / \mathrm{mL}$ & 99.2 & 3.6 & 3 \\
\hline \multicolumn{4}{|l|}{3 freeze-thaw cycles } \\
\hline $300 \mathrm{ng} / \mathrm{mL}$ & 99.4 & 5.0 & 3 \\
\hline $20000 \mathrm{ng} / \mathrm{mL}$ & 99.8 & 2.4 & 3 \\
\hline \multicolumn{4}{|l|}{ In $\mathrm{M}_{9}$ medium, 6 days, $-70^{\circ} \mathrm{C}$} \\
\hline $300 \mathrm{ng} / \mathrm{mL}$ & 93.8 & 3.3 & 3 \\
\hline \multirow[b]{2}{*}{ IS $(5000 \mathrm{ng} / \mathrm{mL})$ in water } & 101 & 3.0 & 3 \\
\hline & 102.9 & 0.74 & 3 \\
\hline $24 \mathrm{hr}, 21-25^{\circ} \mathrm{C}$ & 74.2 & 3.4 & 3 \\
\hline 5 days, $21-25^{\circ} \mathrm{C}$ & 79.5 & 1.7 & 4 \\
\hline
\end{tabular}

TABLE 5: Interference of potential concomitant drugs.

\begin{tabular}{lccc}
\hline Concentration $(\mathrm{ng} / \mathrm{mL})$ & Control & Colistin-MP* & \% dev. \\
\hline 150 & $150 \pm 10$ & $148 \pm 8$ & -1.3 \\
1500 & $1633 \pm 61$ & $1587 \pm 98$ & -2.8 \\
20000 & $20000 \pm 557$ & $19933 \pm 737$ & -0.3 \\
\hline
\end{tabular}

Note. Data represent the mean (SD) of triplicate analysis. ${ }^{*} \mathrm{MP}$ and colistin concentrations were $110 \mu \mathrm{g} / \mathrm{mL}$ and $20 \mu \mathrm{g} / \mathrm{mL}$, respectively, corresponding to the highest concentrations in the in vitro model.

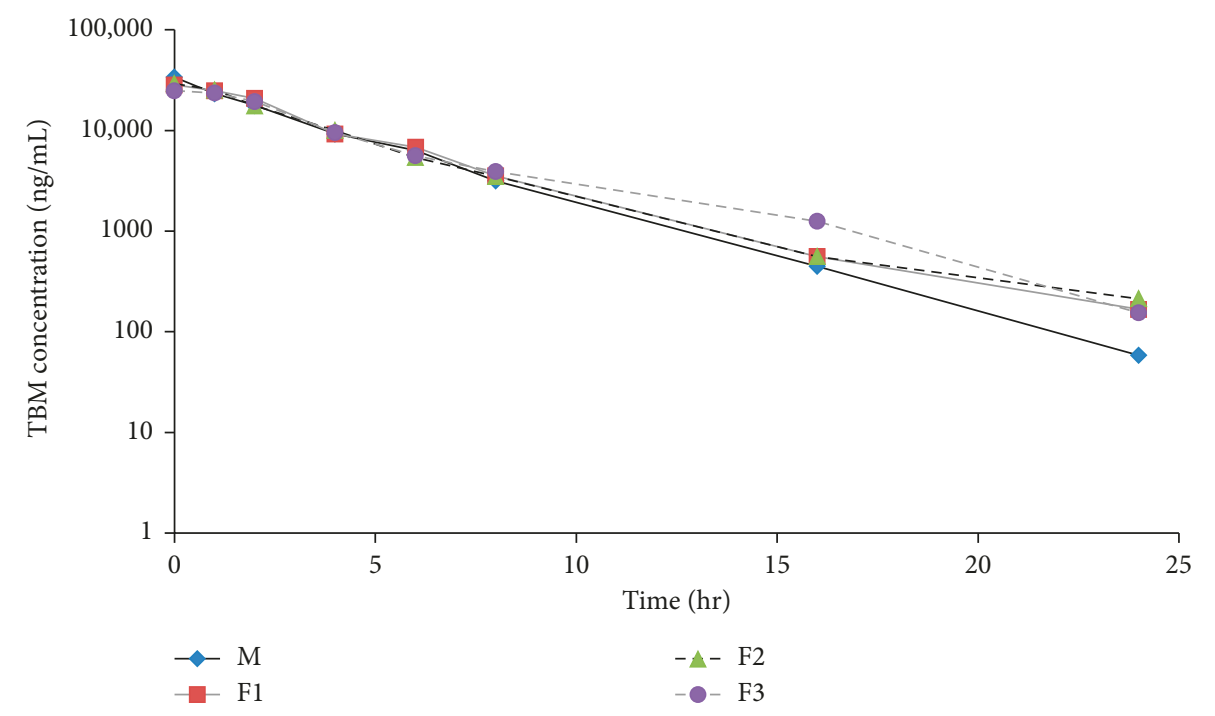

Figure 4: Concentration-time profile of tobramycin from an in vitro PK/PD biofilm model. Samples were taken from the feeding bottle (M) and the tubing outlets from three flow cells with bacterial biofilm (F1, F2, and F3) at designated time intervals.

even smaller, suggesting that IS compensated the matrix effect.

3.2.4. Partial Sample Volume Accuracy. As the target Cmax is $40000 \mathrm{ng} / \mathrm{mL}$, we evaluated accuracy of the assay with an extrahigh QC (40000 ng/mL) when half sample volume was used. The precision and accuracy from six replicates of analysis were $2.2 \%$ and $2.6 \%$, respectively. Therefore, samples above the upper limit of quantification could be analyzed with a partial volume.

3.2.5. Stability. TBM was stable in $\mathrm{M}_{9}$ medium. No significant degradation was found under tested condition (Table 4). Further investigation is ongoing to define longterm stability in $-70^{\circ} \mathrm{C}$ freezer. 
3.2.6. Evaluation of Concomitant Drug Interference. The samples from the supported study are expected to contain MP and colistin; therefore, impact of these drugs on quantification of TBM was evaluated. In the presence of $110 \mu \mathrm{g} / \mathrm{mL} \mathrm{MP}$ and $20 \mu \mathrm{g} / \mathrm{mL}$ colistin, the low, medium, and high QC samples could still be quantified accurately, with a small percent deviation from the samples without these drugs (Table 5).

3.3. Application. The method was applied to determine TBM concentrations used in an in vitro $\mathrm{PK} / \mathrm{PD}$ biofilm simulator. The PK/PD analysis was reported elsewhere [15]. A representative concentration-time curve from the model is showed in Figure 4. The results demonstrate that the sensitivity of the method met the requirement of the intended study.

\section{Conclusion}

TCA not only improves peak shape and retention time of TBM but also increases MS signal intensity of TBM. Using a simple dilution with ion pairing reagent TCA, a sensitive LC-MS/MS method was developed and validated for determination of TBM in bacterial $\mathrm{M}_{9}$ medium. The LLOQ was $50 \mathrm{ng} / \mathrm{mL}$. The sensitivity of the assay met the requirement of the intended PK/PD study in an in vitro biofilm model system.

TCA has been used to increase retention time and sensitivity for quantification of gentamicin, kanamycin, and apramycin [14]. Here, we demonstrated application of TCA to quantification of TBM. We speculate this approach could be generalized: by addition of ion-pairing agents to samples instead of adding to mobile phase solvents, we could extend the retention time of analytes and even increase sensitivity. Acidic ion-pairing agents such as TFA and TCA could be applied to basic polar analytes such as amine-containing analytes, and basic ion-pairing agents could be added to samples of acidic polar analytes. Nevertheless, the concentration of the ion-pairing agent is critical, and selection of the ion-pairing agent is also critical.

\section{Disclosure}

This work was presented in the ACS National Meeting (http:// sanfrancisco2017.acs.org/i/803418-253rd-american-chemicalsociety-national-meeting-expo/89). Its contents are solely the responsibility of the authors and do not necessarily represent the official views of the NIH.

\section{Conflicts of Interest}

All authors declare that they have no conflicts of interest.

\section{Acknowledgments}

This work was supported by a grant (1R01 AI097380-0121) from the National Institute of Allergy and Infectious Diseases of the National Institutes of Health and fund from the
Department of Clinical Pharmacy at the University of California San Francisco.

\section{Supplementary Materials}

Figure S1: effect of TFA on retention time of isoniazid. Figure S2: optimization of TCA concentration. (Supplementary Materials)

\section{References}

[1] E. J. Begg and M. L. Barclay, "Aminoglycosides-50 years on," British Journal of Clinical Pharmacology, vol. 39, no. 6, pp. 597-603, 1995.

[2] H. C. Neu, “Tobramycin: an overview," Journal of Infectious Diseases, vol. 134, pp. S3-S19, 1976.

[3] C. H. Feng, S. J. Lin, H. L. Wu, and S. H. Chen, "Trace analysis of tobramycin in human plasma by derivatization and highperformance liquid chromatography with ultraviolet detection," Journal of Chromatography B, vol. 780, no. 2, pp. 349-354, 2002.

[4] J. A. Statler, "Determination of tobramycin using highperformance liquid chromatography with pulsed amperometric detection," Journal of Chromatography B: Biomedical Sciences and Applications, vol. 527, pp. 244-246, 1990.

[5] C. Ghinami, V. Giuliani, A. Menarini, F. Abballe, S. Travaini, and T. Ladisa, "Electrochemical detection of tobramycin or gentamicin according to the European Pharmacopoeia analytical method," Journal of Chromatography A, vol. 1139, no. 1, pp. 53-56, 2007.

[6] F. Lai and T. Sheehan, "Enhancement of detection sensitivity and cleanup selectivity for tobramycin through pre-column derivatization," Journal of Chromatography A, vol. 609, no. 12, pp. 173-179, 1992.

[7] B. G. Keevil, S. J. Lockhart, and D. P. Cooper, "Determination of tobramycin in serum using liquid chromatography-tandem mass spectrometry and comparison with a fluorescence polarisation assay," Journal of Chromatography B, vol. 794, no. 2, pp. 329-335, 2003.

[8] M. X. Guo, L. Wrisley, and E. Maygoo, "Measurement of tobramycin by reversed-phase high-performance liquid chromatography with mass spectrometry detection," Analytica Chimica Acta, vol. 571, no. 1, pp. 12-16, 2006.

[9] P. M. Bernardi, F. Barreto, and T. Dalla Costa, "Application of a LC-MS/MS method for evaluating lung penetration of tobramycin in rats by microdialysis," Journal of Pharmaceutical and Biomedical Analysis, vol. 134, pp. 340-345, 2016.

[10] L. Huang, P. Lizak, C. C. Dvorak, F. Aweeka, and J. LongBoyle, "Simultaneous determination of fludarabine and clofarabine in human plasma by LC-MS/MS," Journal of Chromatography B, vol. 960, pp. 194-199, 2014.

[11] J. A. J. Haagensen, D. Verotta, L. Huang, A. Spormann, and K. Yang, "New in vitro model to study the effect of human simulated antibiotic concentrations on bacterial biofilms," Antimicrobial Agents and Chemotherapy, vol. 59, no. 7, pp. 4074-4081, 2015.

[12] P. A. Flume, P. J. Mogayzel Jr., K. A. Robinson et al., “Clinical Practice Guidelines for Pulmonary Therapies C: cystic fibrosis pulmonary guidelines: treatment of pulmonary exacerbations," American Journal of Respiratory and Critical Care Medicine, vol. 180, no. 9, pp. 802-808, 2009.

[13] D. J. Touw, A. J. Knox, and A. Smyth, "Population pharmacokinetics of tobramycin administered thrice daily and 
once daily in children and adults with cystic fibrosis," Journal of Cystic Fibrosis, vol. 6, no. 5, pp. 327-333, 2007.

[14] C. Cheng, S. R. Liu, D. Q. Xiao, and S. Hansel, "The application of trichloroacetic acid as an ion pairing reagent in LC-MS-MS method development for highly polar aminoglycoside compounds," Chromatographia, vol. 72, no. 1-2, pp. 133-139, 2010.

[15] J. Haagensen, D. Verotta, L. Huang, J. Engel, A. M. Spormann, and K. Yang, "Spatiotemporal pharmacodynamics of meropenem- and tobramycin-treated Pseudomonas aeruginosa biofilms," Journal of Antimicrobial Chemotherapy, vol. 72, no. 12, pp. 3357-3365, 2017. 

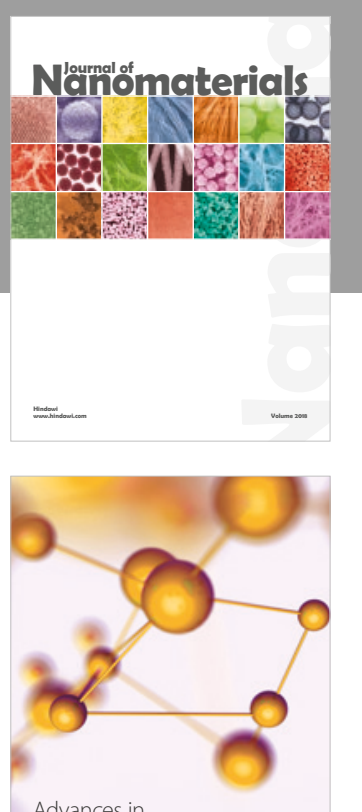

Physical Chemistry
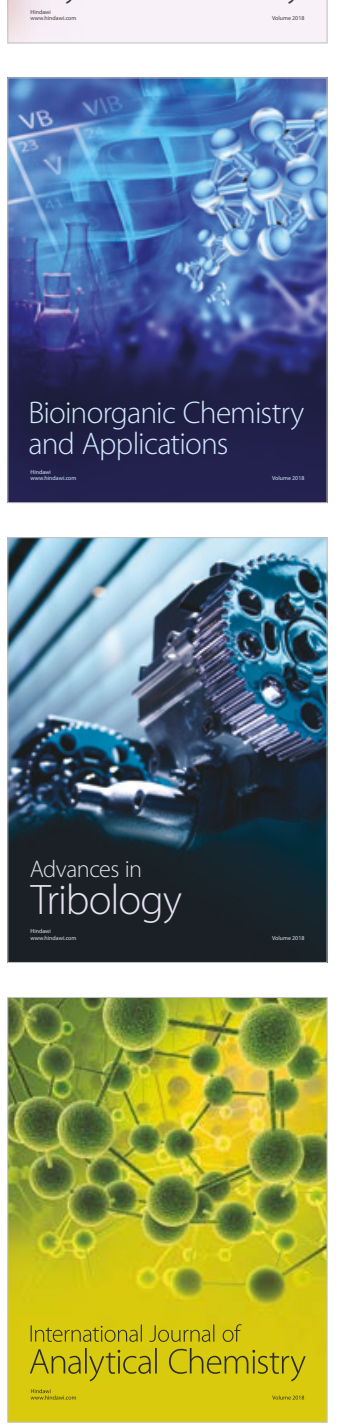

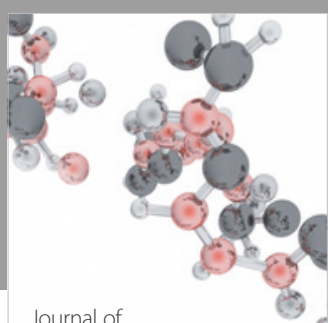

Analytical Methods

in Chemistry

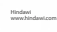

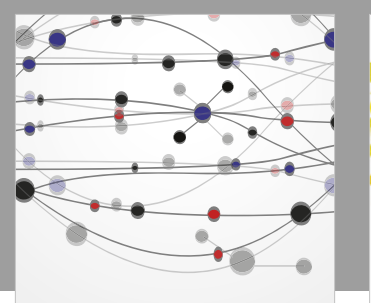

The Scientific World Journal

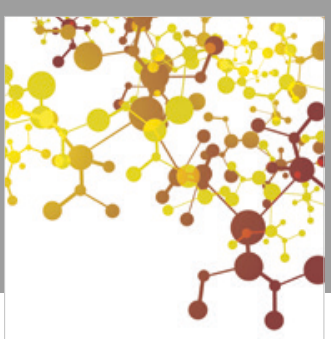

Journal of

Applied Chemistry
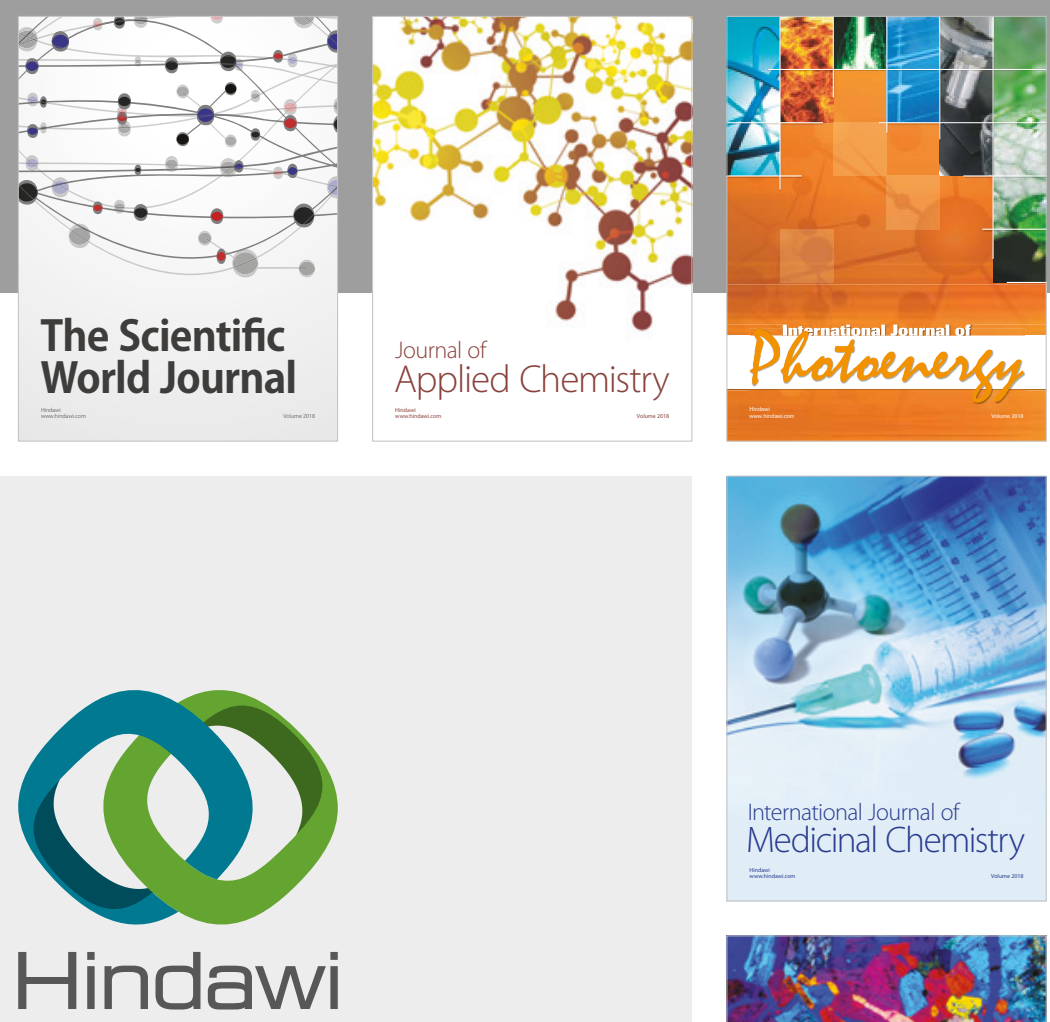

Submit your manuscripts at

www.hindawi.com
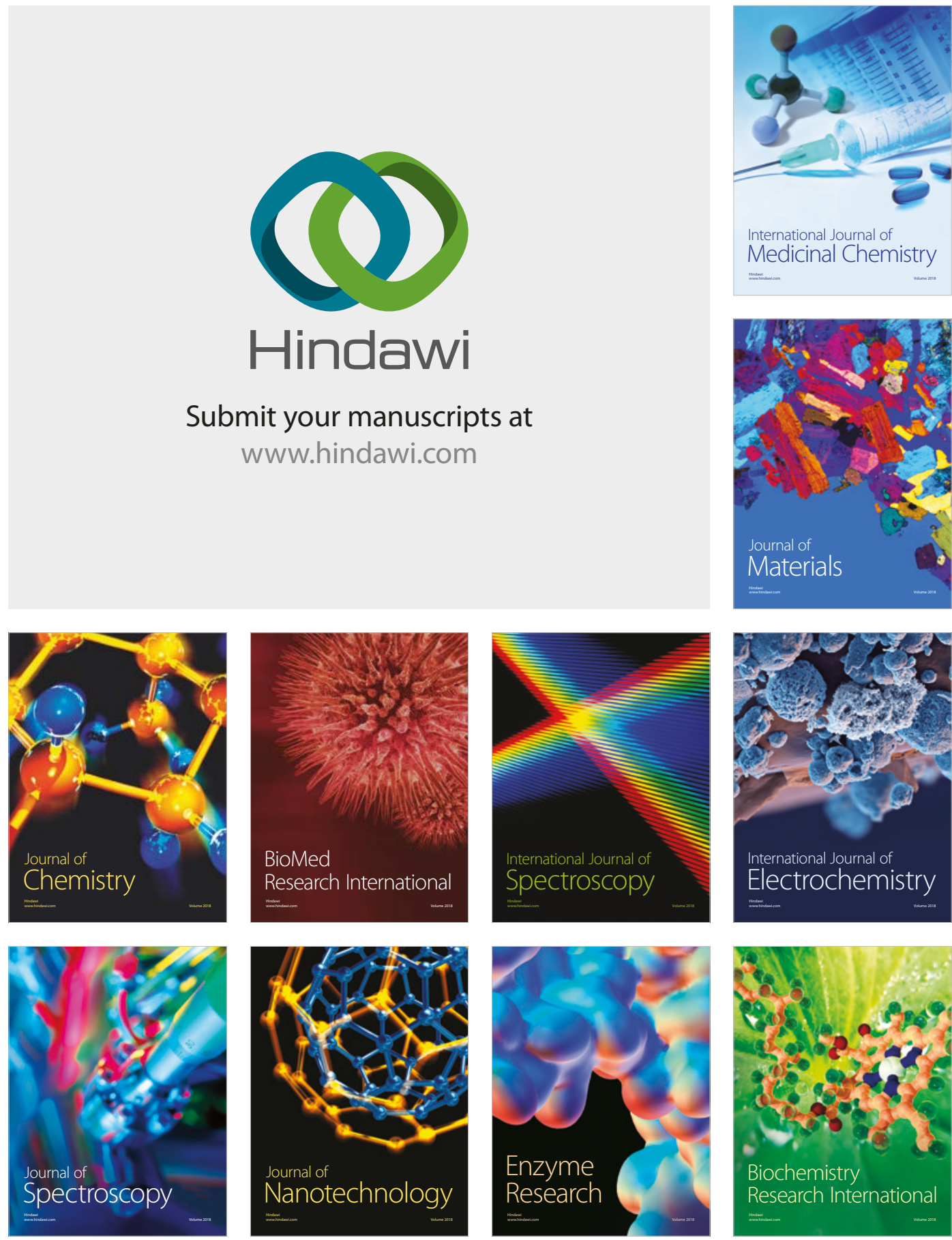
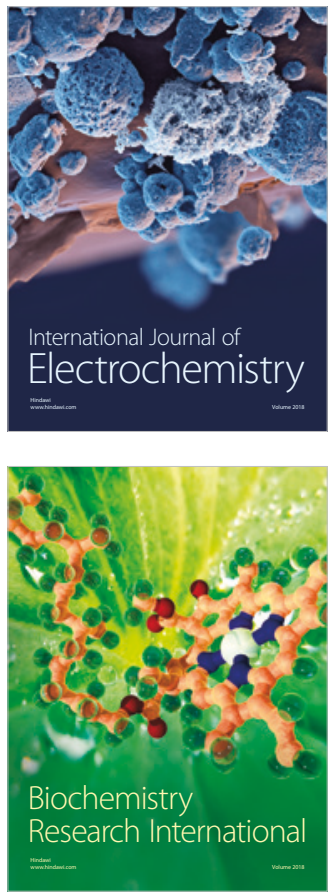